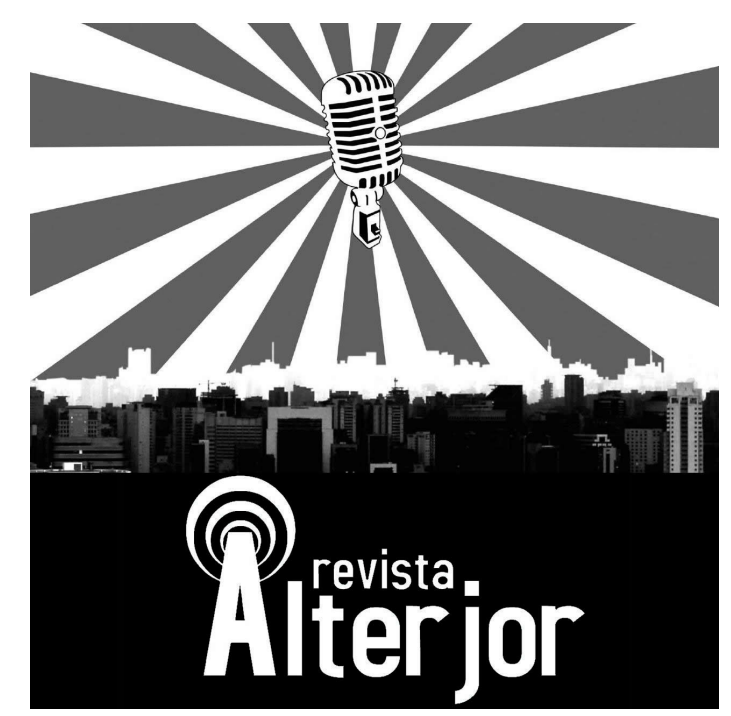

\title{
ELEIÇÕES 2020: QUAL É O PERFIL DE COR/RAÇA E GÊNERO DOS CANDIDATOS E DOS ELEITOS?
}

\author{
Deisy Cioccari ${ }^{1}$ \\ Romer Mottinha ${ }^{2}$
}

\begin{abstract}
RESUMO: O presente trabalho trata-se de uma pesquisa sobre as eleições municipais de 2020 no Brasil, com abordagem sobre comparação do perfil de gênero e cor/raça dos registros das candidaturas e o perfil de gênero e cor/raça dos eleitos. Os cargos em disputa foram para prefeito, vice-prefeito e vereador. A metodologia utilizada foi de pesquisa quantitativa e de estatística descritiva, a qual permite identificar quantas candidaturas foram registradas e analisar os perfis por segmentos. $O$ questionamento principal da pesquisa é sobre qual a diferença de percentual de candidaturas e de eleitos nos segmentos de gênero e de cor/raça? A hipótese do trabalho é que sejam preenchidas as cotas de gênero nas candidaturas e que prevaleça o gênero masculino e a cor/raça branca tanto nas candidaturas quantos entre os eleitos. Os resultados preliminares demonstram que o predomínio do gênero masculino e da cor branca é superior nas candidaturas e predominante entre os eleitos.
\end{abstract}

PALAVRAS-CHAVE: Eleição. Candidatos. Gênero. Raça. Comunicação.

ABSTRACT: The present work is a research on the 2020 municipal elections in Brazil, with an approach on comparing the gender and color / race profile of the candidacy records and the gender and color / race profile of those elected. The disputed positions were for mayor, deputy mayor and councilor. The methodology used was quantitative research and descriptive statistics, which allows identifying how many applications were registered and analyzing the profiles by segments. The main question of the research is about what is the difference in the percentage of candidates and those elected in the gender and color / race segments? The hypothesis of the work is that the gender quotas are filled in the candidacies and that the male gender and the white color / race prevail both in the candidacies and among those elected. The preliminary results demonstrate that the predominance of the male gender and the white color is superior in the candidacies and predominant among the chosen ones.

KEYWORDS: Election. Candidates. Genre. Breed. Communication.

\footnotetext{
${ }^{1}$ Pós-doutoranda em Comunicação pela Faculdade Cásper Líbero. E-mail: deysicioccari@gmail.com

2 Possui graduação em Ciência Política pelo Centro Universitário Internacional (2013) e mestrado em Ciência Política pela Universidade Federal do Paraná (2014). Atualmente é pesquisador do Centro Universitário Internacional. E-mail: romermottinha@gmail.com
}

\section{Revista ALTERJOR}

Grupo de Estudos Alterjor: Jornalismo Popular e Alternativo (ECA-USP)

Ano 11 - Volume 02 - Edição 24 - Julho-Dezembro de 2021

Av. Professor Lúcio Martins Rodrigues, 443, Cidade Universitária, São Paulo, CEP: 05508-020 


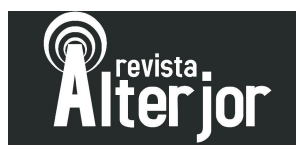

\section{Introdução}

O ano de 2020 foi um período atípico no contexto global em razão da pandemia do coronavírus (COVID-19), em praticamente todas as áreas. As determinações de medidas de distanciamento social foram implementadas, fato este que forçou a sociedade a novas adaptações. Mudanças significativas ocorreram nas esferas da saúde, esportes, economia, educação, turismo, meio ambiente e também na política. Neste contexto as eleições sofreram com adiamentos de datas em vários países, inclusive no Brasil. Normalmente as eleições brasileiras são em primeiro e segundo turno, no primeiro e no último domingo do mês de outubro, respectivamente. Todavia em 2020 as datas da realização do pleito foram em 15 de novembro para o primeiro turno e 29 de novembro para o segundo turno.

Outra alteração importante foi nas regras eleitorais, em específico na restrição de coligações proporcionais. Ou seja, os partidos não podem concorrer em chapas de vários partidos para o cargo de vereador. Os registros de candidaturas devem ser todos em partido isolado na disputa para o Legislativo. Essa medida permite aumentar o número de possíveis candidatos para as câmaras municipais, visto que a lista permite $150 \%$ o número de cadeiras em disputa (Exemplo: se na Câmara Municipal tem 10 cadeiras de vereador os partidos podem lançar até 15 candidatos em suas listas). ${ }^{3}$ As disputas de prefeito e vice-prefeito continuam com a possibilidade de coligações majoritárias.

Em 2016 foram 496.927 registros de candidaturas para as eleições municipais. Para as eleições municipais de 2020 o Tribunal Superior Eleitoral quantificou 557.406 registros de candidaturas para os cargos de prefeito, vice-prefeito e vereador no Brasil. Destas candidaturas 533.510 foram consideradas aptas para disputar o pleito. Então com o fim das coligações proporcionais já foi constatado um aumento de participantes como candidatos.

O Brasil nos últimos anos passou por crises de imoralidades, crises econômicas e crises políticas, tendo impactos em escândalos de corrupção, na ineficiência da gestão

\footnotetext{
${ }^{3}$ Conforme o Art. 10 da Lei 9504/1997 cada partido ou coligação poderá registrar candidatos para a Câmara dos Deputados, a Câmara Legislativa, as Assembleias Legislativas e as Câmaras Municipais no total de até $150 \%$ (cento e cinquenta por cento) do número de lugares a preencher.
}

\section{Revista ALTERJOR}

Grupo de Estudos Alterjor: Jornalismo Popular e Alternativo (ECA-USP)

Ano 11 - Volume 02 - Edição 24 - Julho-Dezembro de 2021 


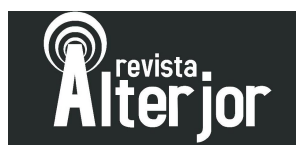

pública, no impeachment de 2016, nos protestos nas ruas e na representação política. Além destas dificuldades o país enfrenta recorrentes problemas de violência contra as mulheres e racismo na sociedade. Neste contexto as eleições são ferramentas que permitem aos cidadãos mudanças na representação política. No sistema eleitoral brasileiro vigora a legislação de cota de $30 \%$ de gênero para as candidaturas. ${ }^{4}$ Todavia esses recursos ainda não permitem que o acesso aos cargos políticos seja distribuído de forma mais equivalente entre os brasileiros, em especial na representação de gênero para mulheres e em relação a cor/raça.

Então, as eleições seriam o momento privilegiado em que os eleitores poderiam punir ou recompensar os políticos: onde bons políticos seriam reeleitos e os que apresentaram desempenho ruim seriam substituídos. Esse controle eleitoral tem fundamentação em um elemento retrospectivo, de avaliação dos que já estão no poder (NICOLAU, 2017, p. 64). Em vista disso, uma possibilidade para real mudança na representatividade não seria uma distribuição das cadeiras dos cargos políticos não apenas proporcional à quantidade de habitantes do município, mas também em relação ao gênero e à cor / raça? Com base nesta problematização esta pesquisa tem o objetivo de demonstrar como foi a distribuição e a diferença das candidaturas entre gênero e cor/raça e qual foi o resultado do perfil dos eleitos nas eleições municipais de 2020 no Brasil.

A hipótese do estudo é que sejam preenchidas apenas as cotas de gênero nas candidaturas e que prevaleça o gênero masculino e a cor/raça branca tanto nas candidaturas quantos entre os eleitos. Então serão trabalhadas as seguintes probabilidades:

- Hipótese I: a probabilidade de distribuição de gênero das candidaturas é apresentada no limite da legislação de cotas de 30\% e 70\% de mínimo e máximo para ambos os sexos;

- Hipótese II: as candidaturas de cor/raça branca tendem a superar todas as demais (pardos, negros, amarelos e indígenas);

\footnotetext{
${ }^{4}$ Conforme o Art. 10 da Lei 9504/1997 cada partido ou coligação preencherá o mínimo de 30\% (trinta por cento) e o máximo de $70 \%$ (setenta por cento) para candidaturas de cada sexo.
}

\section{Revista ALTERJOR}

Grupo de Estudos Alterjor: Jornalismo Popular e Alternativo (ECA-USP)

Ano 11 - Volume 02 - Edição 24 - Julho-Dezembro de 2021 Av. Professor Lúcio Martins Rodrigues, 443, Cidade Universitária, São Paulo, CEP: 05508-020 


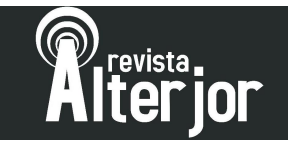

- Hipótese III: estima-se que as candidaturas de homens brancos são as predominantes entre gênero e cor/raça;

- Hipótese IV: a distribuição de gênero para os eleitos não prevalece a regra de cotas para candidaturas, prevalecendo o domínio de homens entre os eleitos;

- Hipótese V: assim como nas candidaturas a cor/raça branca tende a apresentar mais eleitos perante as demais cores/raças;

- Hipótese VI: entre os eleitos espera-se identificar o homem branco com os maiores percentuais de sucesso eleitoral entre as possibilidades de perfil de gênero e cor/raça.

\section{Política e gênero}

A literatura tem se dedicado progressivamente em avaliar quais são os caminhos percorridos pelos indivíduos que almejam a um lugar entre o restrito grupo das elites eletivas. No Brasil, alguns trabalhos têm estudado a identificação das variáveis que afetam as condições daqueles que entram nas disputas eleitorais (CODATO; CERVI; PERISSINOTTO, 2013, p. 61).

Entre as variáveis explicativas sociais com significância estatística como condicionante para o sucesso eleitoral ser mulher apresenta resíduo negativo com o fato de 'ser eleito' e positivo com 'não ser eleito'. Enquanto que os homens não apresentam resíduos significativos (CODATO; CERVI; PERISSINOTTO, 2013, p. 70-71).

As mulheres estão submetidas a várias pressões que prejudicam sua constituição como atores políticos. São insuladas numa esfera doméstica separada do espaço público, têm seu tempo comprimido pela responsabilidade que precisam assumir na gestão do lar e no cuidado com as pessoas mais vulneráveis, controlam menos recursos econômicos, são estigmatizadas se assumem a defesa dos próprios interesses ou se participam da disputa pelo poder. (MIGUEL, 2014, p. 302-303).

O contexto de participação das mulheres na política é recente, pois, sob a ótica dos movimentos feministas, as mobilizações se localizavam inicialmente mais limitadas

\section{Revista ALTERJOR}

Grupo de Estudos Alterjor: Jornalismo Popular e Alternativo (ECA-USP)

Ano 11 - Volume 02 - Edição 24 - Julho-Dezembro de 2021 Av. Professor Lúcio Martins Rodrigues, 443, Cidade Universitária, São Paulo, CEP: 05508-020 


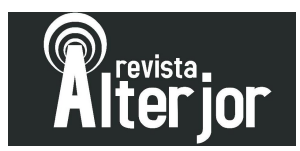

ao protagonismo em instituições variadas da sociedade. Demandas posteriores de ocupação de cargos se fundamentaram na existência de interesses específicos de mulheres, o que justificava a necessidade de uma construção da representação tendo como pedestal os requisitos de gênero. Foi no reconhecimento da pertinência da função das mulheres nos espaços de poder que despontou o debate sobre as condições e possibilidades de formação de representantes capacitadas. Então, a participação das mulheres na esfera política vem demandando uma reflexão sobre o papel das dinâmicas institucionais e das interações mais amplas que se efetivam nos variados campos da atividade social, interferindo na construção e incremento das candidaturas (BARREIRA; GONÇALVES, 2012, p. 315).

A progressiva participação das mulheres na vida política deve ser vista sob a perspectiva das alterações sociais, culturais e políticas da sociedade. Entre estas mudanças, o surgimento de novas famílias, a ruptura dos padrões familiares patriarcais, as novas formas de produção no mundo do trabalho com impacto sobre as relações sociais que acabaram por abalar as estruturas seculares sobre as quais se assentava a dominação masculina em todas as esferas da vida pública e privada (AVELAR, 2002, p. 40).

Já em Eric Hobsbawm (1995), a ascensão de qualquer mulher a postos de destaque político antes da Segunda Guerra Mundial não é se quer pensado. Somente na segunda metade do século XX por meio do movimento feminista se tem a percepção da feminização do poder como processo histórico da conquista feminina no acesso as estruturas sociais, econômicas, políticas e culturais. Nos anos de 1990, se reconhece os limites da "política de ideias" pela busca de "política de presença" (PHILIPS,1995). Na contemporaneidade, apesar de a mulher ocupar cada vez mais os espaços públicos, na qualidade de "trabalhadora extradomiciliar como co-provedora ou provedora do grupo familiar", os papéis construídos e demarcados socialmente de homem e de mulher (mãe cuidadora e homem provedor) ainda remetem à presença feminina na ocupação de espaços nas áreas da assistência social, saúde, educação ou meio ambiente.

Em vez de focalizar a vida interna dos partidos políticos, alguns pesquisadores que estudam a política de elites legislativas, gênero e raças estão com frequência mais

\section{Revista ALTERJOR}

Grupo de Estudos Alterjor: Jornalismo Popular e Alternativo (ECA-USP)

Ano 11 - Volume 02 - Edição 24 - Julho-Dezembro de 2021 Av. Professor Lúcio Martins Rodrigues, 443, Cidade Universitária, São Paulo, CEP: 05508-020 


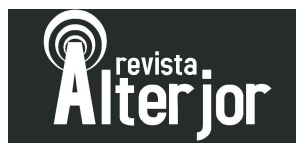

interessados em entender primeiramente o resultado do processo de seleção. O tema do sistema eleitoral básico tem sido promovido pela agenda de muitas democracias consolidadas. Em sistemas eleitorais proporcionais, a magnitude distrital tem sido apresentada como um fator importante, com mais mulheres sendo usualmente eleitas em distritos de alta magnitude. Uma comparação mundial da proporção de mulheres em parlamentos confirma que elas mulheres são melhor sucedidas onde vigoram listas de representação proporcional (NORRIS, 2013, p. 16-18).

As políticas de igualdade de oportunidades são elaboradas para providenciar um nível em que as mulheres possam almejar às carreiras políticas nas mesmas condições que os homens. As políticas de igualdade de oportunidades são valiosas a longo prazo, em especial quando combinadas com outras estratégias, todavia, por si próprias, na maior parte das vezes elas mostram ter pouco impacto em aumentar a representação feminina (NORRIS, 2013, p. 18).

É necessário destacar que além do instrumento de cotas, há outras maneiras de contribuir para o aumento no número de mulheres em eleições. O Estado pode contribuir positivamente com as campanhas femininas quando os partidos se encontram em posições de relutância. Uma maneira de fazer isso é por meio dos fundos partidários destinados a mulheres (KROOK; NORRIS, 2014).

No estágio das candidaturas, os recursos e o suporte para vencer a eleição devem ser assegurados. O acesso aos recursos financeiros é fundamental. Além disso, a organização de arrecadação de dinheiro para candidaturas de mulheres aumenta a taxa de sucesso nas campanhas. Por isso, é necessário a regulamentação dos fundos partidários (KROOK; NORRIS, 2014).

As mulheres são um excelente exemplo para se ter uma ideia de quanto é longo o caminho da luta pela extensão real dos direitos de cidadania aos muitos segmentos de minorias de uma sociedade. Apesar das mulheres brasileiras serem mais da metade da população e do eleitorado, com maior nível de escolaridade e representando quase a metade da população economicamente ativa, apresentam uma subrrepresentação política. Dizendo em outras palavras, como a democratização de uma sociedade é oriunda de um

\section{Revista ALTERJOR}

Grupo de Estudos Alterjor: Jornalismo Popular e Alternativo (ECA-USP)

Ano 11 - Volume 02 - Edição 24 - Julho-Dezembro de 2021 Av. Professor Lúcio Martins Rodrigues, 443, Cidade Universitária, São Paulo, CEP: 05508-020 


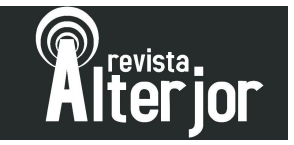

longo processo de mudanças que vão incorporando os grupos minoritários nos benefícios dos direitos que igualam os indivíduos, indistintamente, na esfera política, social e econômica (AVELAR, 2002, p. 44). Considerando que, historicamente, a política se constitui como um território masculino, a ausência das mulheres foi vista por longo tempo como um fenômeno natural das características intrínsecas e pela predileção ao espaço doméstico, o desinteresse pelos negócios públicos ou a racionalidade inferior. A partir do século XX se tem uma outra perspectiva das mulheres com a extensão dos direitos políticos, votar e ser votado. (MIGUEL; FEITOSA, 2009).

\title{
3. Política e Cor/Raça
}

$\mathrm{O}$ autor Florestan Fernandes e toda sua geração de pesquisadores marcou profundamente a reflexão sobre as relações raciais no Brasil. A tese fundamental de Fernandes (1978) pode ser resumida da seguinte forma: a sociedade pós-abolição não criou as condições necessárias para a absorção do elemento negro. O negro não estava preparado social e psicologicamente para se tornar um trabalhador livre.

\begin{abstract}
Os resultados de nossas investigações, apresentados de modo tão sumário, patenteiam que a transição do regime escravocrata para o regime de classes não operou com a mesma rapidez que a transformação do status politico do negro. A medida legal abolicionista, promulgada sob o governo monárquico e consagrada pelo governo republicano que o substitui em 1889 concedeu aos manumitidos direitos formais, o que levaria um dos paladinos do movimento abolicionista a afirmar que a Abolição se revelara uma ironia atroz. É que a transição precisava se operar como um processo histórico-social: o negro deverá antes ser assimilado à sociedade de classes, para depois ajustar-se às novas condições de trabalho e ao novo status econômico-político que adquiria na sociedade de Classes. (BASTIDE; FERNANDES, 1971, p.71-80).
\end{abstract}

O legado de nossas relações escravistas marcaria profundamente a população negra, dificultando sua inserção no mercado de trabalho e perpetuando condições de anomia no seu meio social. Uma posição diferente de Fernandes, mas não mais otimista, mostra que em termos de processo de estratificação e mobilidade social, se as pessoas entram na arena competitiva com os mesmos recursos, exceto na filiação racial, o resultado é uma posição inferior aos não-brancos (HASENBALG, 1979, p.114). Observe-

\section{Revista ALTERJOR}

Grupo de Estudos Alterjor: Jornalismo Popular e Alternativo (ECA-USP)

Ano 11 - Volume 02 - Edição 24 - Julho-Dezembro de 2021 Av. Professor Lúcio Martins Rodrigues, 443, Cidade Universitária, São Paulo, CEP: 05508-020 


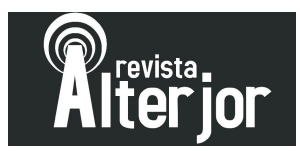

se que o autor usa a expressão não-brancos que inclui todos os indivíduos que possuem características fenotípicas que se aproximam do negro. Telles (2003, p.301-302) observa que o racismo e a discriminação existem em todas as sociedades multirraciais. A especificidade do racismo brasileiro se deve às condições históricas, demográficas, culturais, politicas e econômicas de nossa formação.

O poder seguidamente se refere e apela à exceção, emergência e a uma noção ficcional do inimigo. Ele também cultiva para formular semelhante exceção, emergência e inimigo ficcional. Que a raça tenha um lugar que se destaca na racionalidade própria do biopoder é totalmente justificável. Pois, mais do que o pensamento de classe, a raça foi a obscuridade sempre presente sobre o pensamento e a prática das políticas do Ocidente, em especial ao se tratar de presumir a desumanidade de povos estrangeiros, ou dominálos (MBEMBE, 2016, p. 128).

É pouco possível que a população negra estivesse celebrando os princípios abstratos da liberdade ao aclamar o advento da emancipação. Quando aquele "enorme lamento humano lançou-se ao vento e atirou suas lágrimas ao mar - livre, livre, livre”, a população negra não estava com tendências a um entusiasmo religioso. Essas pessoas sabiam muito bem o que queriam: mulheres e homens desejavam intensamente possuir terras, almejavam votar e "estavam dominados pelo desejo por escolas" (DAVIS, 2016, p. 109).

Os temas raciais e de gênero na política brasileira vêm sendo amplamente debatidos, especialmente no campo institucional. A diversidade e a pluralidade da sociedade no país pouco são representadas no poder Legislativo em que o perfil predominante são de homens brancos: dos congressistas eleitos no Brasil em 2018, 85\% são homens e 74,7\% são brancos (CHAVES; MANCUSO, 2020, p. 2). Na desigualdade de gênero, mesclam-se elementos materiais e simbólicos, que concorrem para a redução da capacidade de ação política das mulheres. O mesmo se pode dizer da desigualdade racial. Por motivos históricos, a população negra e indígena tende a controlar uma parcela menor da riqueza material e sofrer os efeitos de um discurso racista, menos ou mais aberto, que deslegitima sua expressão. O racismo alimenta a privação material,

\section{Revista ALTERJOR}

Grupo de Estudos Alterjor: Jornalismo Popular e Alternativo (ECA-USP)

Ano 11 - Volume 02 - Edição 24 - Julho-Dezembro de 2021 Av. Professor Lúcio Martins Rodrigues, 443, Cidade Universitária, São Paulo, CEP: 05508-020 


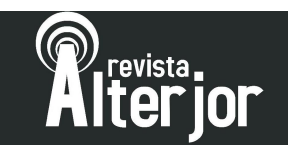

prejudicando negras e negros na competição econômica, ao mesmo tempo que a maior pobreza da comunidade negra aparece como evidência de sua inferioridade (MIGUEL, 2014, p. 303).

\section{Metodologia da Pesquisa}

A metodologia utilizada é de pesquisa quantitativa de estatística descritiva, que se preocupa com a coleta, descrição e apresentação de dados observados, sem tirar conclusões mais genéricas e não se ocupa de valores amostrais (CERVI, 2017, p. 38). Este método permite identificar quantos candidatos foram inscritos para o pleito e quantos destes foram considerados aptos, relacionar os perfis de gênero e de cor/raça e analisar por cruzamento de tabelas o perfil dos eleitos. O objeto da pesquisa são os candidatos a prefeito(a), vice-prefeito(a) e a vereador(a) das eleições municipais do Brasil em 2020. Os dados sobre as candidaturas dos partidos foram selecionados pelo repositório de dados do Tribunal Superior Eleitoral - TSE. Duas categorias de planilhas foram coletadas do TSE: I) relação de candidatos com registros aptos e II) relação de candidatos eleitos. Os detalhes das candidaturas nos bancos de dados do TSE possuem informações sobre gênero, partidos, estado civil, grau de instrução, faixa etária, pirâmide etária, cor/raça e ocupação. Todavia os dados utilizados a seguir nesta pesquisa são somente de cruzamento de tabelas por candidato / eleitos por gênero e cor/raça.

\section{Perfil dos candidatos em 2020 (Cor/Raça e Gênero)}

O IBGE pesquisa a cor ou raça da população brasileira com fundamentação na autodeclaração. Conforme a coleta da Pesquisa Nacional por Amostra de Domicílios (PNAD) 2019, 42,7\% dos brasileiros se declararam como brancos, 46,8\% como pardos, 9,4\% como pretos e 1,1\% como amarelos ou indígenas (IBGE, 2019).

\section{Revista ALTERJOR}

Grupo de Estudos Alterjor: Jornalismo Popular e Alternativo (ECA-USP)

Ano 11 - Volume 02 - Edição 24 - Julho-Dezembro de 2021 Av. Professor Lúcio Martins Rodrigues, 443, Cidade Universitária, São Paulo, CEP: 05508-020 


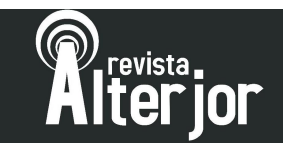

QUADRO 1 - PERFIL DAS CANDIDATURAS - ELEIÇÕES 2020 - COR/RAÇA Abrangência: Brasil

\begin{tabular}{|l|l|l|}
\hline Gênero & Quantitativo & Porcentagem (\%) \\
\hline Amarela & 1.867 & 0,35 \\
\hline Indígena & 2.086 & 0,39 \\
\hline Sem Informação & 6.074 & 1,14 \\
\hline Preta & 55.815 & 10,46 \\
\hline Parda & 210.523 & 39,46 \\
\hline Branca & 257.145 & 48,2 \\
\hline TOTAL & 533.510 & 100 \\
\hline
\end{tabular}

Fonte: Tribunal Superior Eleitoral (2020).

Nota: Dados trabalhados pelos autores.

No quadro 1 pode-se verificar que as candidaturas que prevalecem são as de cor/raça branca e parda, todavia há uma inversão na maioria entre brancos e pardos em comparação com os dados do IBGE. Ou seja, no Brasil a população autodeclarada parda é maior que a autodeclarada branca, porém as candidaturas em 2020 que prevaleceram foram as brancas. Nota-se que os amarelos, indígenas e pretos são em proporções menores tanto na coleta do IBGE quanto na relação de candidaturas para as eleições municipais de 2020. Então as proporcionalidades nestes segmentos são esperadas com números aproximadamente relativos do IBGE com o TSE.

\section{Revista ALTERJOR}

Grupo de Estudos Alterjor: Jornalismo Popular e Alternativo (ECA-USP)

Ano 11 - Volume 02 - Edição 24 - Julho-Dezembro de 2021 


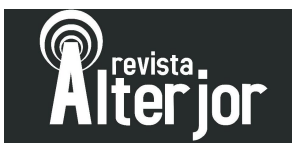

FIGURA 1 - Infográfico de candidaturas em 2020 no Brasil por cor/raça

Cor $/$ Raça (\%) das candidaturas no Brasil - eleições municipais 2020

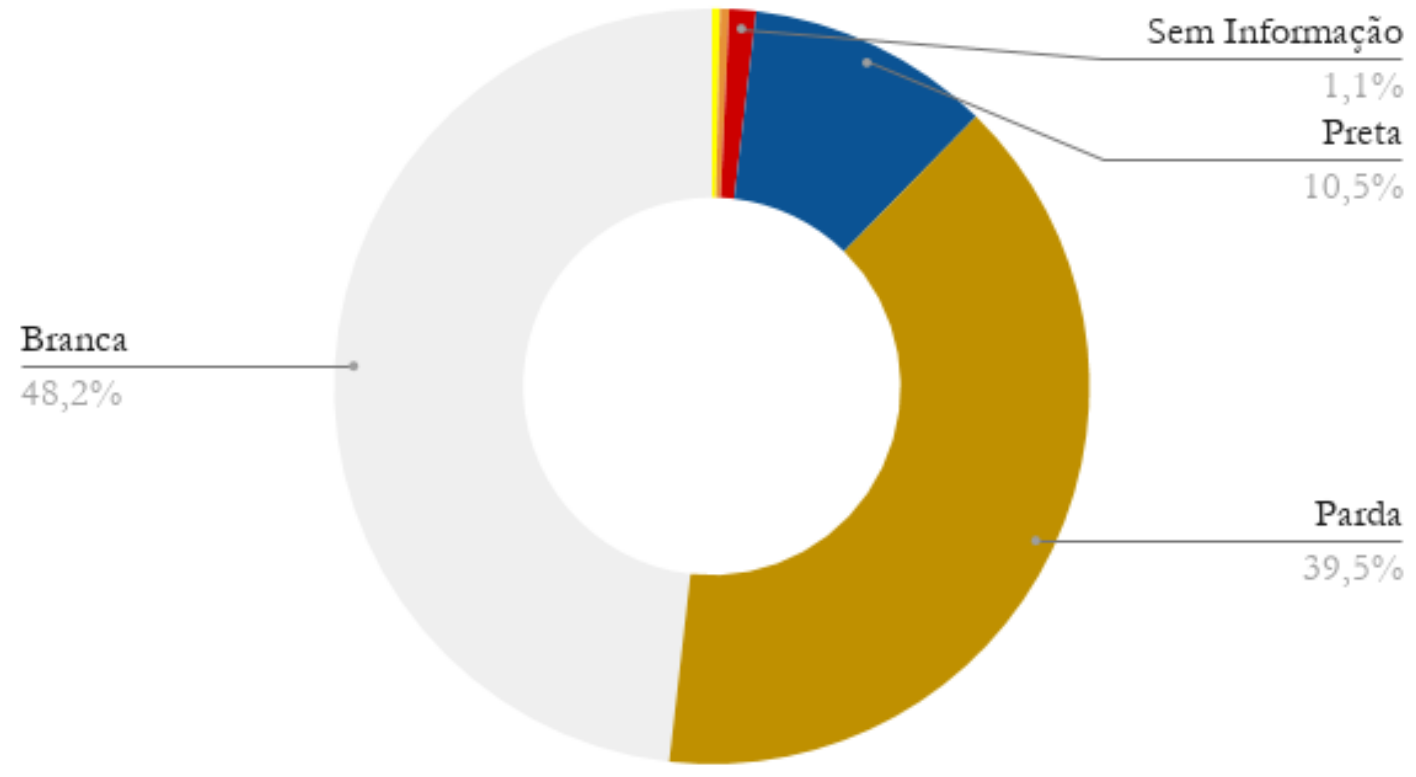

Fonte: Tribunal Superior Eleitoral (2020).

Nota: Dados trabalhados pelos autores.

Conforme os dados da PNAD Contínua (Pesquisa Nacional por Amostra de Domicílios Contínua) 2019, o número de mulheres no Brasil é superior ao de homens. A população brasileira é composta por $48,2 \%$ de homens e $51,8 \%$ de mulheres. Os dados sobre gênero servem para mapear as diferenças entre homens e mulheres e fornecer informações que fundamentem políticas públicas para reduzir as disparidades no acesso à justiça e bem-estar que existem entre os gêneros (IBGE, 2019). Porém, ao verificarmos o perfil das candidaturas em 2020 nota-se que há uma significativa disparidade entre homens e mulheres, conforme exposto no quadro 2.

\section{Revista ALTERJOR}

Grupo de Estudos Alterjor: Jornalismo Popular e Alternativo (ECA-USP)

Ano 11 - Volume 02 - Edição 24 - Julho-Dezembro de 2021 


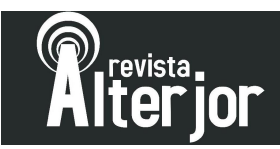

QUADRO 2 - PERFIL DAS CANDIDATURAS - ELEIÇÕES 2020 - GÊNERO

\begin{tabular}{|l|l|l|}
\hline \multicolumn{2}{|c|}{ Abrangência: Brasil } \\
\hline Gênero & Quantitativo & Porcentagem (\%) \\
\hline Feminino & 178.380 & 33,44 \\
\hline Masculino & 355.130 & 66,56 \\
\hline
\end{tabular}

Fonte: Tribunal Superior Eleitoral (2020).

Nota: Dados trabalhados pelos autores.

Apesar de no país o número de mulheres seja superior ao de homens, o que se verificou nas candidaturas de 2020 foi um cumprimento da cota de gênero de $30 \%$ mínima para um dos sexos. Ou seja, conforme o infográfico da figura 2 o qual indica 33,4\% de candidaturas de mulheres, a inserção feminina na política eletiva no Brasil apresenta uma significativa desvantagem já na primeira etapa da disputa eleitoral.

FIGURA 2 - Infográfico de candidaturas em 2020 no Brasil por gênero

\section{Gênero (\%) das candidaturas no Brasil - eleições municipais 2020}

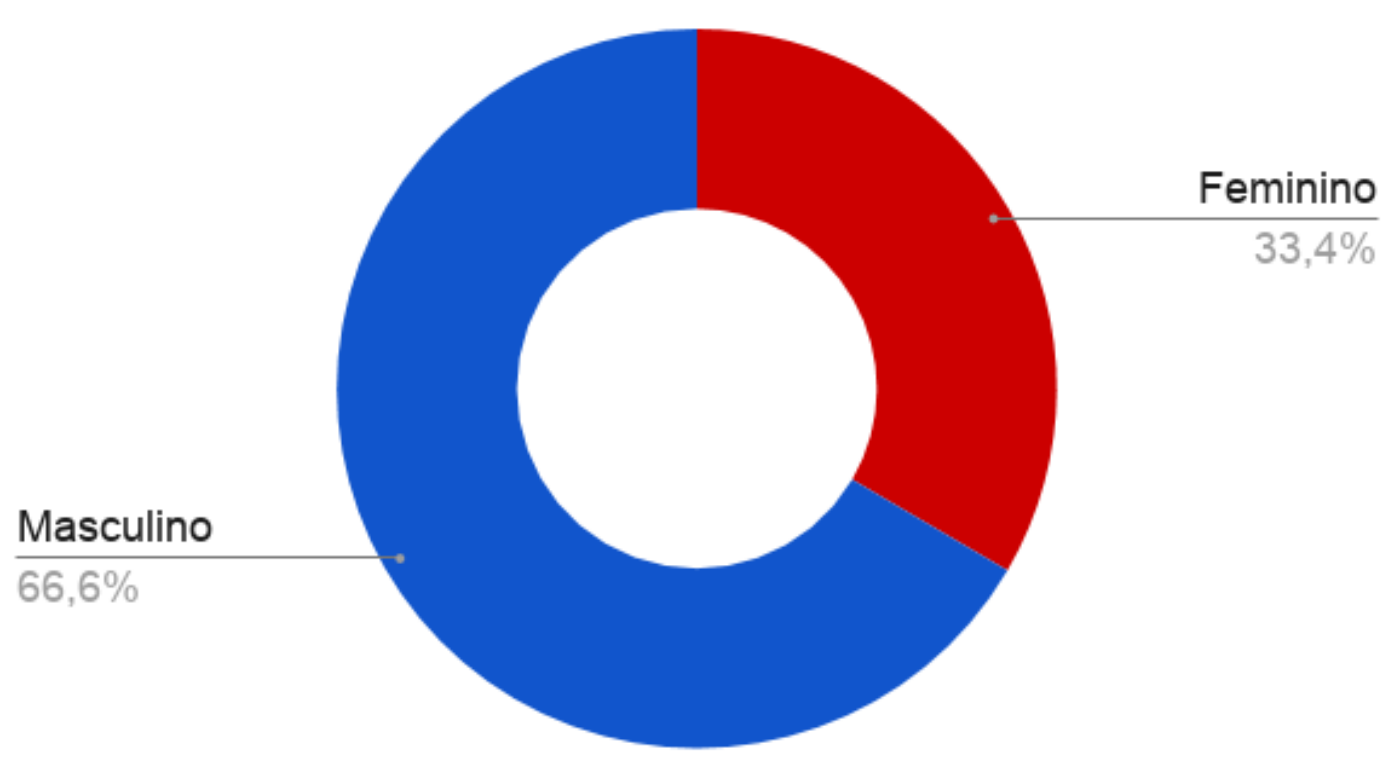

Fonte: Tribunal Superior Eleitoral (2020).

Nota: Dados trabalhados pelos autores.

Em relação às candidaturas em 2020 nos segmentos cor/raça + gênero verifica-se que prevalece o gênero masculino em todas as raças. Conforme pode-se observar no

\section{Revista ALTERJOR}

Grupo de Estudos Alterjor: Jornalismo Popular e Alternativo (ECA-USP)

Ano 11 - Volume 02 - Edição 24 - Julho-Dezembro de 2021 Av. Professor Lúcio Martins Rodrigues, 443, Cidade Universitária, São Paulo, CEP: 05508-020 


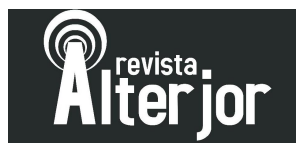

quadro 3 há uma distribuição de certa forma padronizada para candidaturas femininas um pouco acima dos $30 \%$ e um pouco acima dos $60 \%$ masculinas para a cor/raça amarela, indígena, preta, parda e branca. Ou seja, não houve uma equidade para as candidaturas femininas em relação à nenhuma cor/raça, pois todas preencheram a margem dos $30 \%$ das cotas exigidas na legislação eleitoral.

QUADRO 3 - PERFIL DAS CANDIDATURAS - ELEIÇÕES 2020 - COR/RAÇA E GÊNERO

\begin{tabular}{|l|l|l|l|}
\hline \multicolumn{4}{|c|}{ Abrangência: Brasil } \\
\hline Cor/Raça & Gênero & Quantitativo & Porcentagem (\%) \\
\hline Amarela & Feminino & 662 & 35,46 \\
\hline Amarela & Masculino & 1.205 & 64,54 \\
\hline Branca & Feminino & 88.593 & 34,45 \\
\hline Branca & Masculino & 168.552 & 65,55 \\
\hline Indígena & Feminino & 692 & 33,17 \\
\hline Indígena & Masculino & 1.394 & 66,83 \\
\hline Parda & Feminino & 67.291 & 31,96 \\
\hline Parda & Masculino & 143.232 & 68,04 \\
\hline Preta & Feminino & 19.087 & 34,2 \\
\hline Preta & Masculino & 36.728 & 65,8 \\
\hline Sem Informação & Feminino & 2.055 & 33,83 \\
\hline Sem Informação & Masculino & 4.019 & 66,17 \\
\hline
\end{tabular}

Fonte: Tribunal Superior Eleitoral (2020).

Nota: Dados trabalhados pelos autores.

Ao separarmos os gêneros por categorização de cor/raça nas candidaturas das eleições municipais de 2020, conforme o quadro 4, podemos constatar que a cor/raça branca prevalece sobre as demais entre os homens e as mulheres. Em seguida a cor/raça parda é a segunda com número de candidaturas para homens e mulheres, o que já se observou anteriormente nas candidaturas com filtro apenas de cor/raça.

\section{Revista ALTERJOR}

Grupo de Estudos Alterjor: Jornalismo Popular e Alternativo (ECA-USP)

Ano 11 - Volume 02 - Edição 24 - Julho-Dezembro de 2021 Av. Professor Lúcio Martins Rodrigues, 443, Cidade Universitária, São Paulo, CEP: 05508-020 


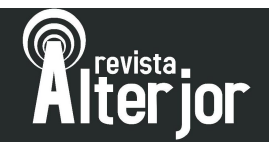

QUADRO 4 - PERFIL DAS CANDIDATURAS - ELEIÇÕES 2020 - GÊNERO E

COR/RAÇA

\begin{tabular}{|l|l|l|l|}
\hline \multicolumn{4}{|c|}{ Abrangência: Brasil } \\
\hline Gênero & Cor/Raça & Quantitativo & Porcentagem (\%) \\
\hline Feminino & Amarela & 662 & 0,37 \\
\hline Feminino & Branca & 88.593 & 49,67 \\
\hline Feminino & Indígena & 692 & 0,39 \\
\hline Feminino & Parda & 67.291 & 37,72 \\
\hline Feminino & Preta & 19.087 & 10,7 \\
\hline Feminino & Sem Informação & 2.055 & 1,15 \\
\hline Masculino & Amarela & 1.205 & 0,34 \\
\hline Masculino & Branca & 168.552 & 47,46 \\
\hline Masculino & Indígena & 1.394 & 0,39 \\
\hline Masculino & Parda & 143.232 & 40,33 \\
\hline Masculino & Preta & 36.728 & 10,34 \\
\hline Masculino & Sem Informação & 4.019 & 1,13 \\
\hline
\end{tabular}

Fonte: Tribunal Superior Eleitoral (2020).

Nota: Dados trabalhados pelos autores.

Por meio da base de dados do TSE pode-se verificar que as candidaturas para as eleições municipais de 2020 no Brasil apresentam mais homens do que mulheres numa relação de cumprimento da legislação eleitoral de 30\% de cotas de gênero. Também destacam-se as candidaturas de cores branca e parda, com poucos pretos e reduzidos amarelos e indígenas.

\section{Perfil dos eleitos em 2020 (Cor/Raça e Gênero)}

Ao se comparar o número de candidaturas com o número de eleitos utilizando as variáveis gênero e cor/raça são necessárias análises dos reflexos decorrentes na política e na sociedade. Ou seja, se uma população apresenta X de homens e Y de mulheres, esperase candidaturas $\mathrm{X}$ de homens e $\mathrm{Y}$ de mulheres e também espera-se o número de eleitos proporcionais a $\mathrm{X}$ de homens e $\mathrm{Y}$ de mulheres. E relativo à proporção também a

\section{Revista ALTERJOR}

Grupo de Estudos Alterjor: Jornalismo Popular e Alternativo (ECA-USP)

Ano 11 - Volume 02 - Edição 24 - Julho-Dezembro de 2021 Av. Professor Lúcio Martins Rodrigues, 443, Cidade Universitária, São Paulo, CEP: 05508-020 


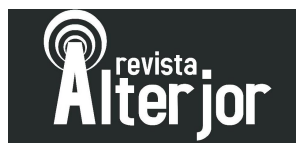

distribuição de candidaturas por declaração de cor/raça, conforme apresenta-se na população, sendo desejável que os eleitos ocupem cargos eletivos de forma minimamente equitativa com os segmentos da população. Todavia, não são estas referências de eleitos que verificaremos nesta seção.

QUADRO 5 - PERFIL DOS ELEITOS - ELEIÇÕES 2020 - COR/RAÇA

\begin{tabular}{|l|l|l|}
\hline \multicolumn{2}{|c|}{ Abrangência: Brasil } \\
\hline Cor/Raça & Quantitativo & Porcentagem (\%) \\
\hline Indígena & 190 & 0,28 \\
\hline Amarela & 263 & 0,39 \\
\hline Sem Informação & 626 & 0,93 \\
\hline Preta & 3.792 & 5,6 \\
\hline Parda & 25.196 & 37,23 \\
\hline Branca & 37.602 & 55,57 \\
\hline TOTAL & 67.669 & 100 \\
\hline
\end{tabular}

Fonte: Tribunal Superior Eleitoral (2020).

Nota: Dados trabalhados pelos autores.

Conforme o quadro 5 e o infográfico da figura 3 o percentual de brancos eleitos é superior ao percentual de candidaturas brancas (em comparação ao quadro 1 e infográfico da figura 1). As candidaturas de brancos tiveram $48,2 \%$ dos registros, mas os eleitos brancos foram 55,6\%, então proporcionalmente foi um resultado superior. Já os de cor parda tiveram $39,5 \%$ de candidaturas e entre os eleitos foram $37,2 \%$, um pouco abaixo apenas da proporção candidaturas $\mathrm{X}$ eleitos.

\section{Revista ALTERJOR}

Grupo de Estudos Alterjor: Jornalismo Popular e Alternativo (ECA-USP)

Ano 11 - Volume 02 - Edição 24 - Julho-Dezembro de 2021 Av. Professor Lúcio Martins Rodrigues, 443, Cidade Universitária, São Paulo, CEP: 05508-020 


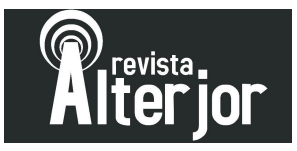

FIGURA 3 - Infográfico de eleitos em 2020 no Brasil por cor/raça

\section{Cor/Raça (\%) dos eleitos no Brasil - eleições municipais 2020}

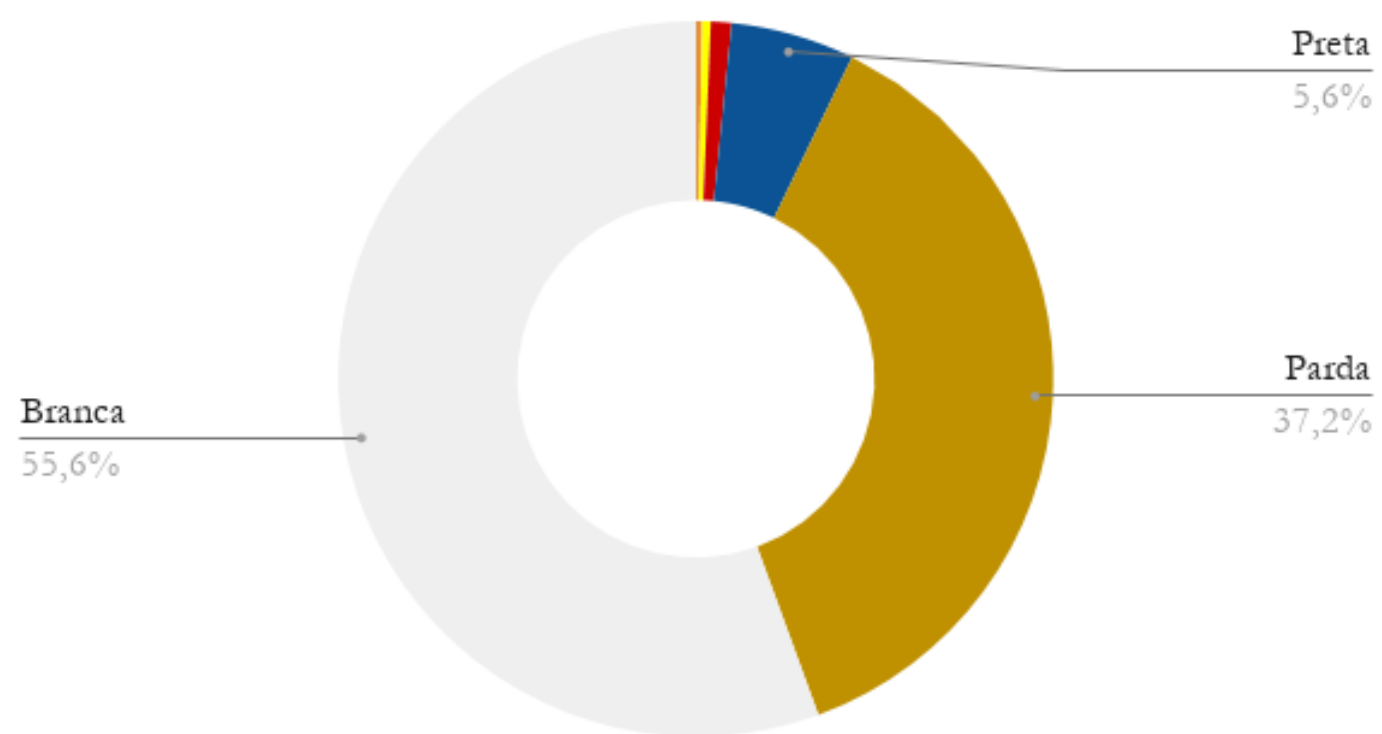

Fonte: Tribunal Superior Eleitoral (2020).

Nota: Dados trabalhados pelos autores.

Já no infográfico da figura 3 pode-se notar uma diferença bastante inferior dos

eleitos de cor preta, com apenas 5,6\%. E este resultado não é apenas baixo em relação aos brancos e pardos, também é baixo em relação aos 10,5\% de candidaturas de pretos. Ou seja, proporcionalmente o sucesso eleitoral é mais baixo que de brancos e pardos.

QUADRO 6 - PERFIL DOS ELEITOS - ELEIÇÕES 2020 - GÊNERO

\begin{tabular}{|l|l|l|}
\hline \multicolumn{3}{|c|}{ Abrangência: Brasil } \\
\hline Gênero & Quantitativo & Porcentagem (\%) \\
\hline Feminino & 10637 & 15,72 \\
\hline Masculino & 57032 & 84,28 \\
\hline
\end{tabular}

Fonte: Tribunal Superior Eleitoral (2020).

Nota: Dados trabalhados pelos autores.

Como já foi mencionado nos tópicos anteriores no Brasil a legislação eleitoral exige cota o mínimo de $30 \%$ de candidaturas para ambos os sexos. Este requisito foi obtido nas candidaturas com $33,44 \%$ de mulheres inscritas. Todavia, os resultados

\section{Revista ALTERJOR}

Grupo de Estudos Alterjor: Jornalismo Popular e Alternativo (ECA-USP)

Ano 11 - Volume 02 - Edição 24 - Julho-Dezembro de 2021 Av. Professor Lúcio Martins Rodrigues, 443, Cidade Universitária, São Paulo, CEP: 05508-020 


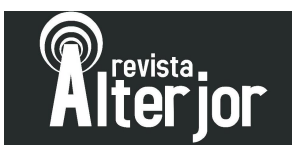

eleitorais ainda são obstáculos para o sucesso eleitoral da mulher brasileira. Pois apenas 15,72\% foram eleitas em 2020. Ou seja, mesmo com cotas para candidaturas a disputa eleitoral ainda demonstra-se desigual na distribuição de cargos políticos eletivos. $\mathrm{Na}$ figura 4 verifica-se o infográfico com a proporção de homens e mulheres eleitas nas eleições de 2020.

FIGURA 4 - Infográfico de eleitos em 2020 no Brasil por gênero
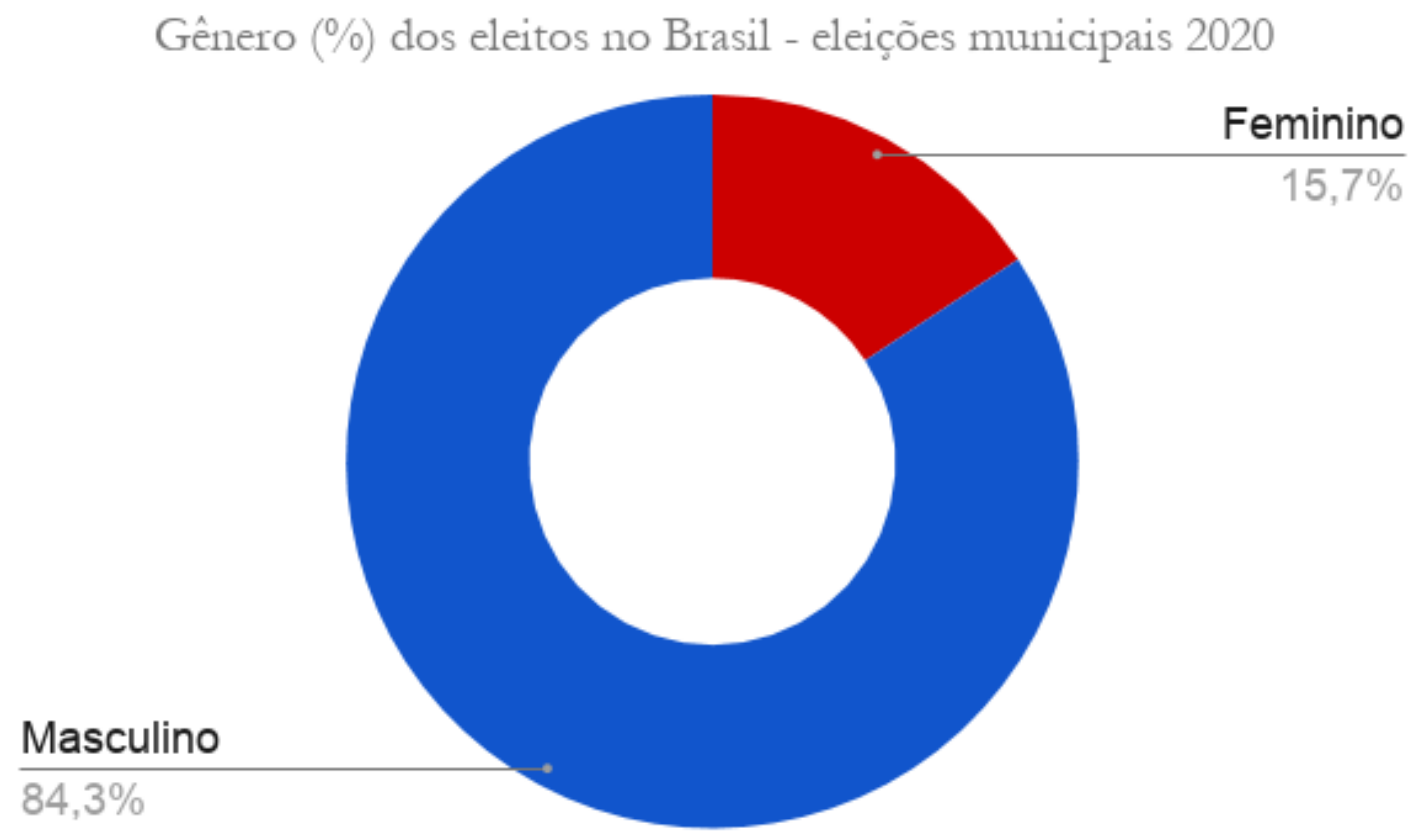

Fonte: Tribunal Superior Eleitoral (2020).

Nota: Dados trabalhados pelos autores.

Quando verificamos o perfil de candidatos em uma eleição podemos fazer análises comparadas em vários segmentos. Nesta pesquisa já verificamos as candidaturas e os eleitos homens prevalecem sobre as mulheres e que as candidaturas e eleitos brancos prevalecem sobre as demais cores/raças. Todavia, podemos questionar se a representação

\section{Revista ALTERJOR}

Grupo de Estudos Alterjor: Jornalismo Popular e Alternativo (ECA-USP)

Ano 11 - Volume 02 - Edição 24 - Julho-Dezembro de 2021 


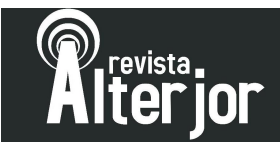

masculina é superior nos resultados eleitorais em todas as cores/raças? Verifica-se no quadro 7 que a resposta é sim.

QUADRO 7 - PERFIL DOS ELEITOS - ELEIÇÕES 2020 - COR/RAÇA E GÊNERO

\begin{tabular}{|l|l|l|l|}
\hline \multicolumn{5}{|c|}{ Abrangência: Brasil } \\
\hline Cor/Raça & Gênero & Quantitativo & Porcentagem (\%) \\
\hline Amarela & Feminino & 53 & 20,15 \\
\hline Amarela & Masculino & 210 & 79,85 \\
\hline Branca & Feminino & 6372 & 16,95 \\
\hline Branca & Masculino & 31230 & 83,05 \\
\hline Indígena & Feminino & 31 & 16,32 \\
\hline Indígena & Masculino & 159 & 83,68 \\
\hline Parda & Feminino & 3554 & 14,11 \\
\hline Parda & Masculino & 21642 & 85,89 \\
\hline Preta & Feminino & 532 & 14,03 \\
\hline Preta & Masculino & 3260 & 85,97 \\
\hline Sem Informação & Feminino & 95 & 15,18 \\
\hline Sem Informação & Masculino & 531 & 84,82 \\
\hline
\end{tabular}

Fonte: Tribunal Superior Eleitoral (2020).

Nota: Dados trabalhados pelos autores.

\section{Revista ALTERJOR}

Grupo de Estudos Alterjor: Jornalismo Popular e Alternativo (ECA-USP)

Ano 11 - Volume 02 - Edição 24 - Julho-Dezembro de 2021 


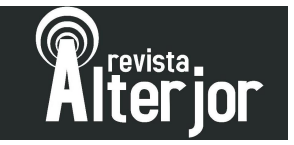

Então, de acordo com os dados do quadro 7 o perfil dos eleitos de cor/raça amarela teve uma distribuição de $20,15 \%$ de mulheres e $79,85 \%$ de homens, que foi o maior percentual de sucesso eleitoral nos segmentos relacionados. Pois brancos e indígenas tiveram $16 \%$ de mulheres eleitas, já pardos e pretos ficaram com 14\% de mulheres eleitas. Nesta análise do perfil dos eleitos por cor/raça aos pares masculino e feminino pode-se constatar o predomínio de homens em todas as cores/raças. Mas há distinção entre as mulheres para o sucesso eleitoral entre cor/raça? No quadro 8 verificamos que a resposta também é sim.

QUADRO 8 - PERFIL DOS ELEITOS - ELEIÇÕES 2020 - GÊNERO E COR/RAÇA

\begin{tabular}{|l|l|l|l|}
\hline \multicolumn{4}{|c|}{ Abrangência: Brasil } \\
\hline Gênero & Cor/Raça & Quantitativo & Porcentagem (\%) \\
\hline Feminino & Amarela & 53 & 0,5 \\
\hline Feminino & Branca & 6372 & 59,9 \\
\hline Feminino & Indígena & 31 & 0,29 \\
\hline Feminino & Parda & 3554 & 33,41 \\
\hline Feminino & Preta & 532 & 5 \\
\hline Feminino & Sem Informação & 95 & 0,89 \\
\hline Masculino & Amarela & 210 & 0,37 \\
\hline Masculino & Branca & 31230 & 54,76 \\
\hline Masculino & Indígena & 159 & 0,28 \\
\hline Masculino & Parda & 21642 & 37,95 \\
\hline Masculino & Preta & 3260 & 5,72 \\
\hline Masculino & Sem Informação & 531 & 0,93 \\
\hline
\end{tabular}

Fonte: Tribunal Superior Eleitoral (2020)

Nota: Dados trabalhados pelos autores

Os dados apresentados no quadro 8 mostram que 59,9\% das mulheres eleitas são brancas e que $54,76 \%$ dos homens eleitos são brancos. Já as mulheres pardas foram

\section{Revista ALTERJOR}

Grupo de Estudos Alterjor: Jornalismo Popular e Alternativo (ECA-USP)

Ano 11 - Volume 02 - Edição 24 - Julho-Dezembro de 2021 Av. Professor Lúcio Martins Rodrigues, 443, Cidade Universitária, São Paulo, CEP: 05508-020 


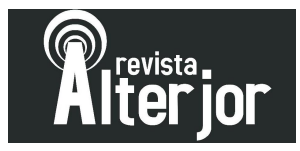

$33,41 \%$ eleitas e homens pardos 37,95\% eleitos. Enquanto que mulheres pretas $5 \%$ eleitas e homens pretos 5,72\% eleitos. Então verifica-se em comparação de percentuais das candidaturas com os eleitos que o espaço de cotas das mulheres é tomado pelos homens, quando analisamos a proporção de mulheres que se candidataram com a proporção de mulheres que se elegeram. Também foi possível constatar que a proporção de brancos eleitos é superior à proporção de brancos nas candidaturas. Então, os eleitos os brancos obtêm os melhores percentuais de sucesso eleitoral, os pardos uma pequena redução, enquanto que os pretos perdem significativamente a proporção de candidaturas em relação aos eleitos. Amarelos e indígenas tem percentuais abaixo de 1\% tanto em candidaturas quantos entre os eleitos.

Uma observação importante para refletir sobre esta pesquisa de gênero e cor/raça na política é que as eleições municipais são os níveis inferiores dos cargos políticos eletivos. Para uma mensuração mais profunda sobre o acesso das mulheres e de indivíduos não brancos aos cargos eletivos no Brasil recomenda-se uma investigação sobre os eleitos e as candidaturas estaduais e do Congresso. Ou seja, um estudo minucioso sobre as candidaturas e eleitos para deputados estaduais, vice-governadores e governadores na esfera dos Estados e para deputados federais, senadores, vice-presidente e presidente na esfera federal.

\section{Considerações Finais}

Nesta pesquisa, sobre o perfil das candidaturas e eleitos nas eleições municipais do Brasil em 2020, a hipótese I elaborada foi relacionada inicialmente que as cotas de gênero sejam preenchidas nas candidaturas, que pela legislação eleitoral são de $30 \%$. E que prevalece o gênero masculino e a cor/raça branca tanto nas candidaturas quantos entre os eleitos (hipótese II). A hipótese das cotas de gênero foi correspondida nas candidaturas, todavia nos resultados eleitorais ficaram muito abaixo da cota. $\mathrm{O}$ predomínio de homem branco também foi constatado tanto em candidaturas como entre os eleitos (hipótese III e VI). As mulheres levam desvantagem nos resultados eleitorais

\section{Revista ALTERJOR}

Grupo de Estudos Alterjor: Jornalismo Popular e Alternativo (ECA-USP)

Ano 11 - Volume 02 - Edição 24 - Julho-Dezembro de 2021 Av. Professor Lúcio Martins Rodrigues, 443, Cidade Universitária, São Paulo, CEP: 05508-020 


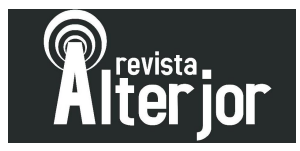

em todos os segmentos de cor/raça (hipótese IV). Os brancos têm melhores resultados eleitorais proporcionalmente comparados com as outras cores/raças (hipótese V).

Ao analisar a competição eleitoral é possível perceber que os negros participam do processo. Nas eleições de 2016, 49\% dos candidatos eram pretos e pardos. No entanto, isso não se mantém no resultado das eleições, já que homens brancos se elegem muito mais do que qualquer outra categoria social, chegando a ter cerca de $40 \%$ das cadeiras no país todo. Processos estruturais somados a uma história de discriminação racial vão moldando as possibilidades de acesso de um grupo. A maioria dos pretos e pardos têm uma experiência de vida que remonta a uma história de pobreza. Se os negros conseguiram um avanço de representatividade nas eleições deste ano, a proporção é ainda distante dos 56\% que esse grupo representa na população brasileira e que evidencia que eles seguem sub-representados na política.

De acordo com dados da pesquisa e da Agência Senado, os negros aumentaram sua participação no comando das prefeituras e no número de cadeiras nas câmaras de vereadores, segundo dados preliminares do Tribunal Superior Eleitoral (TSE). Dos mais de 5,4 mil prefeitos eleitos, aproximadamente 1,7 mil candidatos se declararam pretos ou pardos, o que corresponde a $32 \%$ do total.

As mulheres no Brasil ainda têm uma difícil jornada para conquista de espaço na política em cargos eletivos. Nas eleições municipais de 2020 foram apenas 15,7\% de mulheres eleitas. Nas eleições de 2018 no Brasil na Câmara dos Deputados foram eleitas $15 \%$ de deputadas e no Senado foram eleitas 14\% de senadoras. Então nas duas últimas eleições no Brasil as cotas de $30 \%$ de candidaturas não representaram maior inserção das mulheres em cargos políticos eletivos. A consequência disso é que a desigualdade na representação dos nossos atores políticos deve permanecer ou conquistar avanços em passos lentos, visto que os valores políticos e culturais não têm o desenvolvimento desejável.

\section{Revista ALTERJOR}

Grupo de Estudos Alterjor: Jornalismo Popular e Alternativo (ECA-USP)

Ano 11 - Volume 02 - Edição 24 - Julho-Dezembro de 2021 Av. Professor Lúcio Martins Rodrigues, 443, Cidade Universitária, São Paulo, CEP: 05508-020 


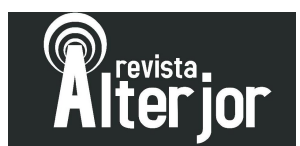

\section{Referências}

AVELAR, Lucia Merces. Mulher e Política: o mito da igualdade. Social Democracia Brasileira, Brasília, p. 40 - 54, 01 mar. 2002.

BARREIRA, Irlys; GONÇALVES, Danyelle Nilin. Presença e ausência de candidatas: mapeando representações de dirigentes partidários. In: José Eustáquio Diniz Alves; Céli Regina Jardim Pinto; Fátima Jordão. (Org.). Mulheres nas eleições 2010. 1ed. São Paulo: ABCP/Secretaria de Políticas para as Mulheres, 2012, p. 315-336.

BRASIL. Lei 9.504/97, de 30 de setembro de 1997. Disponível em: http://www.planalto.gov.br/ccivil_03/leis/L9504.htm . Acesso em 27 dez. 2020.

BRASIL. Tribunal Superior Eleitoral. Estatísticas Eleitorais. Disponível em: https://www.tse.jus.br/eleicoes/estatisticas/estatisticas-eleitorais . Acesso em $27 \mathrm{dez}$. 2020 .

BASTIDE, Roger; FERNANDES, Florestan. Brancos e Negros em São Paulo. São Paulo: Companhia Editora Nacional, 1971.

CERVI, Emerson U. Manual de métodos quantitativos para iniciantes em Ciência Política. Voluma 1, 1ed - Curitiba: CPOP-UFPR, 2017.

CHAVES, Beatriz Mendes; MANCUSO, Wagner Pralon. Raça E Gênero Nas Eleições Brasileiras: Uma Análise Sobre A Influência De Marcadores Sociais Na Disputa À Câmara Dos Deputados E Assembleias Legislativas Em 2018. In: Seminário Discente de Ciência Política da UFPR, I, 2020, Curitiba. Anais do I Seminário Discente de Ciência Política da UFPR (SDCP), Curitiba: UFPR, 2020. Disponível em: https://eventos.ufpr.br/SDCP/SDCP2020/paper/viewFile/3125/929. Acesso em $27 \mathrm{dez}$. 2020.

CODADO, Adriano Nervo; CERVI, Emerson Urizzi; PERISSINOTTO, Renato Monseff. Quem se elege prefeito no Brasil? condicionantes do sucesso eleitoral em 2012. Cadernos Adenauer (São Paulo), v. 14, p. 61-84, 2013.

DAVIS, Angela. Mulheres, raça e classe. Tradução Heci Regina Candiani. - 1. ed. São Paulo: Boitempo, 2016.

FERNANDES, Florestan. A Integração do Negro na Sociedade de Classes. São Paulo: Editora Ática, vol. 2, 1978.

HASENBALG, Carlos Alfredo. Discriminação e Desigualdades raciais no Brasil. Rio de Janeito, Editora Graal, 1979.

HOBSBAWM, Eric. $A$ Era dos Extremos: o Breve Século XX (1914-1991).

Companhia das Letras: São Paulo, 1995.

IBGE - Instituto Brasileiro de Geografia e Estatística. IBGEeduca: População. Pesquisa Nacional por Amostra de Domicílios (PNAD) 2019.

\section{Revista ALTERJOR}

Grupo de Estudos Alterjor: Jornalismo Popular e Alternativo (ECA-USP)

Ano 11 - Volume 02 - Edição 24 - Julho-Dezembro de 2021 Av. Professor Lúcio Martins Rodrigues, 443, Cidade Universitária, São Paulo, CEP: 05508-020 


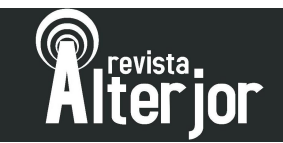

KROOK, Mona Lena; NORRIS, Pippa. Beyond Quotas: Strategies to Promote Gender Equality in Elected Office. Political Studies, 2014, vol.62, p.2-20. Disponível em: http://mlkrook.org/pdf/ps_krook_norris_2014.pdf. Acesso em 27 dez. 2020.

MBEMBE, Achille. Necropolítica. Revista arte e ensaios: Eclipse, n. 32, p. 123-151, 2016. Disponível em: https://revistas.ufrj.br/index.php/ae/article/view/8993 . Acesso em: 26 dez. 2020.

MIGUEL, Luis Felipe; FEITOSA, Fernanda. O gênero do discurso parlamentar: mulheres e homens na tribuna da Câmara dos Deputados. Dados - Revista de Ciências Sociais, vol. 52, n. 1, marzo, 2009, pp. 201-221. Universidade Cândido Mendes. Rio de Janeiro, Brasil.

MIGUEL, Luis Felipe. Democracia e representação: territórios em disputa. $1^{a}$ ed. São Paulo: Editora Unesp, 2014.

NICOLAU, Jairo. Representantes de quem? Os (des)caminhos do seu voto da urna à Câmara dos Deputados. Rio de Janeiro: Zahar, 2017.

NORRIS, Pippa. Recrutamento político. Revista de Sociologia e Política, Curitiba, v. 21, n. 46, Junho 2013. Disponível em: http://www.scielo.br/scielo.php?script=sci_arttext\&pid=S0104-

$44782013000200002 \& \operatorname{lng}=\mathrm{en} \& n \mathrm{~nm}=\mathrm{iso} \& \bar{t} \operatorname{lng}=\mathrm{pt}$. Acesso em 27 dez. 2020.

TELLES, Edward Eric. 2003: Racismo à Brasileira: uma nova perspectiva sociológia. Rio de Janeiro: Relume Dumará. 